https://doi.org/10.30910/turkjans.679908

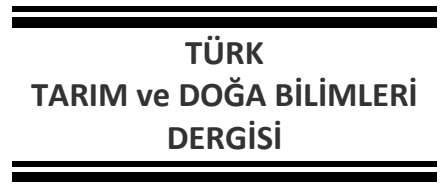

\title{
Araştırma Makalesi
Mardin ve Şırnak illerinde Yetiştiriciliği Yapılan Bazı Zeytin Genotiplerinin Meyve ve Yağ Özelliklerinin Belirlenmesi
}

\author{
Nevzat SEVGIN*, Saime CANER
}

Şırnak Üniversitesi Ziraat Fakültesi Bahçe Bitkileri Bölümü, Şırnak

*Sorumlu yazar: nsevgin@gmail.com

\begin{abstract}
Geliş Tarihi: 25.04.2019
Düzeltme Geliş Tarihi: 16.11.2019

Kabul Tarihi: 18.11.2019

Bu çalışmada Şırnak/Kumçatı, Şırnak/Kızıısu, Şırnak/Cizre, Mardin/Kızıltepe ve Mardin/Derik' ten alınan genotipler Ayvalık ve Gemlik gibi önemli zeytin çeşitleriyle pomolojik ve yağ analizleri bakımından karşılaştırılmıştır. Çalışmada, meyvelerde meyve eni, meyve boyu, meyve indeksi, meyve şekli, meyve ağılığı, meyve eti oranı ve olgunluk indeksine bakılarak pomolojik özellikleri incelenmiş ve mekanik yolla elde edilen zeytinyağı analizlerinde iyot sayısı, peroksit sayısı, toplam fenol miktarı değerlerine bakılmış olup bu özellikler Ayvalık ve Gemlik zeytin çeşitleriyle karşılaştııılmışır. Yapılan ölçümlerde meyve eni bakımından Ayvalık (18.85 $\mathrm{mm}$ ) ve Gemlik (18 mm) çeşitlerine en yakın değeri Kızıltepe $(17.63 \mathrm{~mm})$, meyve boyu bakımından Ayvalık (23.09 $\mathrm{mm}$ ) ve Gemlik $(22.57 \mathrm{~mm})$ çeşitlerine en yakın değeri Kızıltepe $(22.56 \mathrm{~mm})$ ve 100 meyve ağırlığı bakımından yine Ayvalık (498.44 g) ve Gemlik ( $537.35 \mathrm{~g}$ ) çeşitlerine en yakın değeri Kızıltepe ( $372.19 \mathrm{~g}$ ) genotipi göstermiştir. Yağ analizleri sonucunda ise iyot sayısı ve toplam fenol miktarı bakımından Ayvalık ve Gemlik çeşitlerine en yakın değeri Derik genotipi gösterirken peroksit sayısı bakımından ise Kızısu genotipinin bu çeşitlere yakın değer sergilediği görülmüştür. Bu çalışma ile Şırnak/Kumçatı, Şırnak/Cizre, Şırnak/Kızılsu, Mardin/Kızıltepe ve Mardin/Derik'teki zeytin ve zeytinyağı özellikleri incelenmiş bu illerimizdeki zeytin yetiştiriciliğinin ve farkındalığın arttırılması amaçlanmıştır.
\end{abstract}

Özet

Anahtar kelimeler: Zeytin, zeytinyağ, pomoloji, meyve indeksi, olgunluk indeksi.

\section{The Determination of Fruit and Oil Properties of Some Olives Which are Cultivated in Mardin and Şırnak}

\begin{abstract}
This study was carried out genotypes obtained from Şırnak / Kumçatı, Şırnak / Kızılsu, Şırnak / Cizre, Mardin / Kızıltepe and Mardin / Derik were compared with important olive varieties such as Ayvalık and Gemlik in terms of pomological and oil analyzes. In the study, pomological characteristics of fruit were examined by looking at fruit width, fruit height, fruit index, fruit shape, fruit weight, fruit pulp rate and maturity index. In the analysis of olive oil obtained by mechanical method, iodine number, peroxide number, total phenol amount, were examined and compared with Ayvalık and Gemlik olive varieties. In the measurements made, Kızıltepe genotype $(17.63 \mathrm{~mm}$ ) showed the closest value to Ayvalık $(18.85 \mathrm{~mm}$ ) and Gemlik varieties $(18 \mathrm{~mm})$ in terms of fruit width and Kızıltepe genotype $(22.56 \mathrm{~mm})$ showed the closest value to Ayvalık (23.09 $\mathrm{mm})$ and Gemlik varieties $(22.57 \mathrm{~mm}$ ) in terms of fruit length. Also, Kızıltepe genotype (372.19 g) showed the closest value to Ayvalık (498.44 g) and Gemlik (537.35 g) in terms of fruit weight. As a result of oil analysis, Derik genotype showed the closest value to Ayvalık and Gemlik varieties in terms of iodine number and total phenol amount whereas Kızılsu genotype showed a close value to these varieties in terms of peroxide number.
\end{abstract}

Key words: Olive, olive oil, pomology, fruit index, maturity index. 


\section{Giriş}

Dünyanın en eski kültür bitkilerinden olan zeytin (Olea europaea L.) meyvesini tüketimi, yağ üretimi ve depolanabilme özelliği bakımından dünyanın en önemli meyveleri arasında yer almaktadır (Kaniewski ve ark., 2012). Sistematik literatüründe Oleceae familyasının, Olea cinsinin, Olea europa L. türü olarak bilinir (Kiritsakis ve Markakis, 1987). Zeytin yetiştiriciliğinin ilk insanlarla birlikte başladığı kabul edilmekte ve "Zeytin bütün ağaçların ilkidir" denilmektedir. Zeytinin insanlık tarihindeki önemine tüm kutsal kitaplarda, yaradılış ve kuruluş efsanelerinde yer verilmektedir. Arkeolojik ve jeolojik buluntular da zeytinin M.Ö. 6000 yılından beri kullanıldığını göstermektedir (Çavuşoğlu ve Çakır, 1988). Antik dönemde, sofralık yemek, yemek pişirmek, aydınlatmada kullanımının yanı sıra zeytinyağı tıbbi amaçlar için de kullanılmıştır (Zohary ve ark., 2012; Mercuri ve ark., 2013; Valamoti ve ark., 2018). Bugün Türkiye topraklarında yer alan zeytinin anavatanı Güneydoğu Anadolu Bölgesi'ni içine alan Yukarı Mezopotamya ve Güney Ön Asya'dır. Buradan tüm Akdeniz havzasına ve daha sonra Amerika'yı da içine alan çok geniş bir alana yayılmıştır (Şeker ve ark., 2008). Türkiye sahip olduğu Akdeniz iklim özellikleri ve bulunduğu coğrafi konum nedeniyle İspanya, İtalya, Tunus ve Yunanistan gibi diğer Akdeniz ülkeleriyle birlikte dünyanın önde gelen zeytin üreticileri içerisinde yer almaktadır. Günümüzde kaliteli ve yüksek verimli zeytin çeşitleriyle bahçe kurulması ve olgun meyveden zeytinyağının üretimi Akdeniz ülkelerinde zeytincilik uygulamalarının en önemli parçasını oluşturmaktadır (Owen ve ark., 2000). Türkiye'de özellikle Ege ve Akdeniz kıyılarında Akdeniz ikliminin hâkim olduğu yerlerde yaygın olan zeytin üretimi, bu bölgelerdeki tarım işletmelerinin ana üretim dallarından birini oluşturmaktadır. Ege Bölgesi Türkiye sofralık ve yağlık zeytin çeşitlerinin ana üretim bölgesini oluşturmaktadır. Güneydoğu Anadolu Bölgesi zeytin çeşitliliği bakımından en zengin bölgemiz olmasına rağmen zeytin üretim potansiyeli bakımından istenilen seviyenin çok gerisinde kalmaktadır. Bunun sebeplerinden biri bölgeye uygun özellikte çeşitlerle bahçelerin kurulmamasından kaynaklanmaktadır. Son yıllarda piyasada bulunan türlerle bahçelerin kurulması ve mevcut zeytinliklerin yeni çeşitlere çevrilmesinden dolayı yerel zeytin çeşitlerinin orijin bölgelerinde giderek azalması ve hatta yok olması tehlikesiyle karşıya kalmıştır. Zeytinin gen merkezlerinden biri olarak kabul edilen Şırnak ve Mardin illerimizde de uzun yıllardan beri geleneksel bir biçimde yerel genotiplere ile kısmi olarak zeytincilik yapılmaktadır. Ancak bölgede mevcut zeytin genotiplerinin meyve ve yağ kalitesi üzerine yeterli çalışma yapılmamıştır.

Bu çalışmada, Mardin ve Şırnak illerinde zeytin yetiştiriciliği yapılan bölgelerde yetiştirilen zeytin genotiplerinin pomolojik özellikleri ve yağ karakterizasyonu yapılmıştır. Ayrıca, her genotipe ait zeytinyağı örneğinde iyot sayısı, peroksit sayısı, kırılma indeksi ve fenolik bileşik miktar analizleri gerçekleştirilmiştir. Araştırmadaki genotiplerin meyve ve yağ özellikleri Ayvalık ve Gemlik çeşitlerinin özellikleriyle karşılaştırılıp benzerlikler ve farklılıklar belirlenmiştir.

\section{Materyal ve Yöntem}

Araştırmada kullanılan zeytin genotipleri Şırnak/Kumçatı, Şırnak/Kızılsu, Şırnak/Cizre, Mardin/Kızıltepe ve Mardin/Derik ilçelerinden temin edilerek zeytinler pomolojik ve zeytinyağı analizleri için soğuk zincirde laboratuvara getirilmiştir. Temin edilen bu zeytin genotiplerinin olgunlaşma zamanları ve olgunluk indeksi dikkate alınarak hasat edilmiştir. Tüm zeytin örneklerinin pomolojik analizleri Şırnak Üniversitesi Ziraat Fakültesi Bahçe Bitkileri Bölümü laboratuvarlarında yapılmıştır. Pomolojik analizlerin yapılması aşamasında her grupta 15 meyvenin bulunduğu 3 yineleme kullanılmıştır. Pomolojik analizlerin tamamlanmasının ardından tüm zeytinlerden yaklaşık 300-500 g örnek kullanılarak zeytinyağı elde edilmiştir. Zeytin örnekleri çekirdeklerinden ayrılarak elde edilen meyve eti iyice ezildikten sonra +25 ${ }^{\circ} \mathrm{C}^{\prime}$ de santrifüj yardımı ile zeytin yağı ayrıştırılmıştır. Elde edilen zeytinyağlarında yağ asitleri bileşenleri dışında kalan diğer tüm analizler, Çanakkale On sekiz Mart Üniversitesi Ziraat Fakültesi Bahçe Bitkileri Bölümü laboratuarlarında yapılmıştır.

Belirlenen çeşitlerin pomolojik özelliklerinin belirlenmesinde; her bir çeşitten tesadüfi olarak alınan 100 meyvede, meyve tane ağırlığı, 100 meyve ağırlığı, çekirdek ağırlığı, 100 çekirdek ağırlığı (0.1 g'a duyarlı terazi ile), meyve boyu, meyve eni, meyve indeksi (boy/en), Çekirdek boyu, çekirdek eni (0.01 mm'ye duyarlı kumpas ile), Meyve şekli (Canözer, 1991)'e göre tespit edilmiştir.

Olgunluk indeksi; Olgunluk indeksi; her tekerrürden tesadüfi olarak seçilen 100 zeytinde Şeker ve arkadaşlarına (2008) göre tanımlanarak saptanmıştır. Zeytinler ikiye kesilerek; $0=$ Meyve kabuğu koyu yeşil, 1= Meyve kabuğu sarı ya da sarımsı yeşil, 2= Meyve kabuğu sarımsı yeşil ancak üzeri kırmızımsı noktalı, 3= Meyve kabuğu kırmızımsı ya da hafif violet, 4= Meyve kabuğu siyah ve meyve eti tamamen yeşil, 5= Meyve kabuğu siyah ve meyve eti çekirdeğin yarısına doğru violet renkte, $6=$ Meyve kabuğu siyah ve meyve eti hemen çekirdeğe kadar violet, 7= Meyve kabuğu siyah ve 
meyve eti tamamen siyah olmak üzere 8 kategoriye göre sınıflandırılmıştır. Olgunluk indeksi; her sınıfa giren meyve adedi o sınıf değeri ile çarpılarak toplanıp, değerlendirilen toplam meyve sayısına bölünerek hesaplanmıştır.

$$
\text { Olgunluk indeksi = }
$$

$(0 \times n 0)+(1 \times n 1)+(2 \times n 2)+(3 \times n 3)+(4 \times n 4)+(5 \times n 5)+(6 \times n 6$ )$+7 \times n 7) / 100$

Zeytin meyvelerinin yağı, soğuk ekstraksiyon yöntemi ile çıkarılarak, zeytinyağı kalite analizleri yapılıncaya kadar +4 을 de saklanmıştır.

İyot sayısı: Wijs metoduna göre belirlenmiştir. (AOAC, 1990). 0.2 g örnek $15 \mathrm{ml}$ $\mathrm{CCl}_{4}$ 'de çözülmüştür. Üzerine $10 \mathrm{ml} \% 5$ 'lik Civa II Asetat ve $25 \mathrm{ml}$ Wijs çözeltisi ilave edilerek örneğin ağzı kapatılmış ve karanlıkta 3 dakika bekletilmiştir. Üzerine daha sonra $1.990 \mathrm{~g}$ potasyum iyodür ve 100 $\mathrm{ml}$ saf su ilave edilmiş, $0.1 \mathrm{Na}_{2} \mathrm{~S}_{2} \mathrm{O}_{3}$ ile renk açık sarı oluncaya kadar titre edilmiştir. Üzerine 1-2 damla nişasta çözeltisi eklenerek $0.1 \quad \mathrm{Na}_{2} \mathrm{~S}_{2} \mathrm{O}_{3}$ ile renk beyaz oluncaya kadar titre edilmiş ve harcanan $\mathrm{Na}_{2} \mathrm{~S}_{2} \mathrm{O}_{3}$ miktarı saptanmıştır. Aynı işlemler kontrol için yapılarak toplam iyot sayısı belirlenmiştir.

Peroksit sayısı: Yağlarda bulunan aktif oksijen miktarının ölçüsü olup, I kg yağda bulunan peroksit, oksijenin miliekivalan gram olarak miktarıdır (Anonim, 1973; Nas ve ark., 1992). Bu değer zeytinyağında $20 \mathrm{meq} \quad 02 / \mathrm{kg}$ yağı aşmamalıdır. Yağ örneği kloroformda çözülüp asetik asit ve potasyum iyodür ilave edildikten sonra I dakika çalkalanarak karanlık odada 5 dakika bekletilmiş ve bu süre sonunda ayarlı sodyum tiyosülfat ile titre edilmiştir. Araştırma numunesinden analiz için alınacak örnek miktarı, numunenin tahmin edilen peroksit değerine göre Peroksit değeri skalasından faydalanılarak belirlenmiştir.

Toplam fenolik bileşikler: Rastgele seçilen meyvelerden alınan örneklerde Folin Ciocalteu ayıracı ile spektrofotometrik yöntem kullanılarak $\mathrm{mg} / \mathrm{kg}$ olarak Gallik asit cinsinden belirlenmiştir (Zheng ve Wang, 2001).

Denemeden elde edilen veriler JMP.5.01 istatistik paket programı kullanılarak varyans analizine tabi tutulmuş, her çeşidin kendi içindeki ortalamalar arasındaki farklılıklar Duncan testi $(P \leq 0.05)$ ile belirlenmiştir.

\section{Bulgular ve Tartışma}

Çalışma kapsamında kullanılan Zeytin meyvesinin pomolojik özellikleri incelendiğinde Meyve eni bakımından Ayvalık $18.85 \mathrm{~mm}$ ve Gemlik $18 \mathrm{~mm}$ olarak ölçülmüş olup bunlara $17.63 \mathrm{~mm}$ ile Kızıltepe genotipi en yakın değere sahip olurken bunu sırasıyla Derik 16.36 mm, Kumçatı $16.31 \mathrm{~mm}$, Cizre $15.92 \mathrm{~mm}$ ve Kızılsu genotipi $15.72 \mathrm{~mm}$ ile takip etmiştir. Kızılsu genotipi bu değeri ile Ayvalık ve Gemlik çeşitlerine en uzak değeri göstermiştir (Çizelge 1). Daha önceki çalışmalarda ülkemizde yetiştirilen zeytin çeşitlerinin pomolojik özellikleri incelenmiş ve meyve enini Gemlik çeşidinde 17.91 $\mathrm{mm}$, Ayvalık çeşidinde $19.14 \mathrm{~mm}$, Memecik çeşidinde $19.40 \mathrm{~mm}$ olarak saptamıştır (Canözer 1991). Kaynaş ve ark. (1996) Gemlik çeşidinin meyve enini $16,50 \mathrm{~mm}$ Halhalı çeşidinin meyve enini ise $16.80 \mathrm{~mm}$ olarak belirlemişlerdir. Çalışma sonucunda elde edilen değerler literatürdeki değerlerden daha düşük bulunmuştur. Meyve boyu değerlerine bakıldığında Ayvalık $23.09 \mathrm{~mm}$ ve Gemlik $22.57 \mathrm{~mm}$ olarak ölçülmüş olup $22.56 \mathrm{~mm}$ ile Kızıltepe genotipi bu çeşitlere en yakın değerleri gösterirken $24.16 \mathrm{~mm}$ ile Kızılsu genotipi bu iki çeşitten yüksek bir değer sergilemiştir. Diğer genotipler ise sırasıyla Derik $22.10 \mathrm{~mm}$, Cizre 21.74 $\mathrm{mm}$ ve Kumçatı $21.49 \mathrm{~mm}$ olarak ölçülmüştür. Meyve indeksi meyve boyunun meyve enine bölünmesi ile elde edilen değer olarak kabul görmektedir. Bu kapsamda hesaplanan meyve indeksine göre Ayvalık 1.22 ve Gemlik 1.25 olarak hesaplanmış ve meyve şekilleri yuvarlağa yakın oval olarak bulunmuştur. Kızıltepe 1.27 ve Kumçatı 1.31 meyve indeksi ile bu iki çeşide yakın değerler gösterip meyve şekli bakımından Ayvalık ve Gemlik çeşitleriyle aynı sınıfta yer almışlardır. Kızılsu genotipi 1.53 meyve indeksi ile her iki çeşidin üzerinde bir değer sergilemiş olup meyve şekli uzun oval olarak belirlenmiştir. Daha önce yapılan bir çalışmada boy en oranı 1.38 (Canözer, 1991 ) ile 1.53 (Tutar, 2010) arasında belirlenmiştir. Cizre 1.36 ve Derik 1.35 meyve indeksi ile birbirine yakın değerler sergilemiş meyve şekilleri ise oval olarak belirlenmiştir. Meyve tane ağırlıkları bakımından Gemlik 5.37 g, Ayvalık 4.98 g olarak ölçülmüştür. Diğer genotiplerimiz ise sırasıyla Kızıltepe $3.72 \mathrm{~g}$, Kızılsu 3.55 g, Derik 3.38 g, Cizre 3.26 g ve Kumçatı $3.25 \mathrm{~g}$ olarak belirlenmiştir. 100 dane meyve ağırlıklarına bakıldığı zaman ise Gemlik $537.35 \mathrm{~g}$, Ayvalık $498.44 \mathrm{~g}$ olarak belirlenmiştir. Denemeye esas alınan örneklerimiz ise bu her iki çeşitten daha düşük fakat birbirlerine yakın değerler sergilemişlerdir. Buna göre Kızıltepe 372.19 g, Kızılsu 354.71 g, Derik 338.45 g, Cizre 326.21 g ve Kumçatı 324.93 g olarak belirlenmişlerdir.

Meyvelerde et oranı sofralık zeytinlerde kaliteyi belirleyen unsurlardandır. Et oranı çalışmada ele alınan seleksiyon kriterleri arasındadır. Seçilen genotipler arasında et oranı \%88.06-81.74 arasında değişim göstermiştir. \%88.06 ile en yüksek et oranına sahip Kumçatı genotipi çıkmıştır. Kızıltepe (\%84.02) genotiplerinin Ayvalık (\%85.38) ve Gemlik (\%85.36) çeşitlerine yakın değerler sergilediği, Kızılsu (\%81.74) genotipinin ise meyve et oranının bu çeşitlerden az olduğu görülmüştür. Çekirdek eni bakımından 9.4 
mm ile Kızılsu genotipi ilk sırada gelmekte ve Ayvalık (8.18 $\mathrm{mm}$ ) ve Gemlik (8.58 $\mathrm{mm}$ ) çeşitlerinden daha yüksek bir değer göstermiştir. Kızıltepe $7.88 \mathrm{~mm}$, Cizre 7.72 mm, Kumçatı 7.48 mm ölçümleriyle birbirlerine yakın değerler sergilerken Derik 5.01 $\mathrm{mm}$ ile en düşük, aynı zamanda Ayvalık ve Gemlik çeşitlerine en uzak değeri sergilemiştir. Çekirdek boyu bakımından yine ilk sırayı 19.8 mm ile Kızılsu genotipinin aldığı ve Gemlik ve Ayvalık çeşitlerinden ise boy bakımından daha yüksek değer göstermiştir. Bunu sırasıyla Kızıltepe, Ayvalık, Gemlik, Cizre, Kumçatı ve Derik takip etmiştir. Çekirdek tane ağırıkları bakımından ise Ayvalık $0.72 \mathrm{~g}$ ve Gemlik $0.69 \mathrm{~g}$ olarak ölçülmüş olup bunlara en yakın değeri $0.64 \mathrm{~g}$ ile Kızılsu genotipi göstermiştir. Diğer genotiplerin çekirdek tane ağırlıkları ise sırasıyla Kızıltepe 0.59 g, Cizre 0.46 g, Derik 0.42 ve Kumçatı $0.38 \mathrm{~g}$ olarak ölçülmüştür. 100 dane çekirdek ağılıklarına bakıldığı zaman ise Kızılsu genotipi 64.75 g ağırlığı ile Ayvalık (72.85) ve Gemlik (69.05) çeşitlerine daha yakın değer sergilemiştir. Diğer genotipler ise sırasıyla Kızıltepe 59.45 g, Cizre 46.44 g, Derik $42.43 \mathrm{~g}$ ve Kumçatı $38.78 \mathrm{~g}$ olarak ölçülmüştür. Çalışmada kullanılan zeytin genotiplerinden elde edilen zeytinyağlarında belirlenen iyot sayısı, Peroksit sayısı ve toplam Fenol miktarı Çizelge 2 verilmiştir. genotiplerden elde edilen zeytinyağlarının iyot sayıları arasında önemli farklılıklar bulunmuştur. En yüksek iyot sayısı Kızıltepe genotipinde (89.36) en yüksek olur iken en düşük değer $(80,20)$ Ayvalık çeşidinde görülmüştür.

Peroksit sayılarına bakıldığında en yüksek değer $18.53 \mathrm{meq} \mathrm{g} / \mathrm{kg}$ ile Cizre genotipinde gözlenmiş bunu sırası ile Kızıltepe (16.53), Kumçatı (12.70) ve Derik (12.36) genotipi izlemiştir. En düşük değer Ayvalık (10.93 meq $\mathrm{g} / \mathrm{kg}$ ) çeşidinde gözlenmiştir. Toplam Fenol içerikleri bakımından en yüksek toplam fenol miktarının Ayvalık (374.33) ve Gemlik (359.67) çeşitlerinden sonra Derik (292.3) genotipinde olduğu saptanır iken en düşük değer Kızıltepe (153 mg/kg) genotipinde gözlenmiştir. Fenolik bileşikler zeytinyağının kendine özgü aroması ve tadı üzerine etkisi olan bileşiklerdendir. Zeytinyağının stabilite ve kalitesini arttırırlar. Garcia ve ark. (2003)'na göre ticari sızma zeytinyağlarının toplam fenol içeriği ortalama $30-400 \mathrm{mg} / \mathrm{kg}^{\prime}$ dır. Bulunan bütün genotiplerin fenol içeriği bakımından verilen aralıkta yer aldığını göstermektedir.

\section{Sonuç ve Öneriler}

Yapılan çalışmalar sonucunda pomolojik özellikler bakımından önemli sofralık çeşitlerimiz olan Ayvalık ve Gemlik çeşitlerimize Kızıltepe genotipinin daha yakın değer sergilediği görülmüştür. Bu nedenle Kızıltepe genotipinin sofralık olarak değerlendirilmek üzere bölgedeki yetiştiriciliği arttırılabilir. Zeytinyağı analiz sonuçlarına baktığımız zaman ise iyot sayısı ve fenol miktarı bakımından Ayvalık ve Gemlik çeşitlerine en yakın değeri Derik genotipi sergilemiştir. Fenol miktarı bilindiği üzere depolama süresince oksidasyona karşı yağı korur. Zeytinyağının stabilite ve kalitesini arttırır. Peroksit sayısı en düşük olan genotip ise Kızılsu genotipi olmakla beraber çalışmadaki tüm genotiplerimizin peroksit sayısı değeri 20 nin altında bulunmuştur. Peroksit sayısı zeytinyağının yağa işlenme öncesi oksidasyonun ve zeytinyağının muhafaza durumunun göstergesidir. Kaliteli yağ eldesinde ise Derik ve Kızılsu genotiplerinin yetiştiriciliği artırılabilir. Çalışmanın yapıldığı bölge zeytinin gen merkezlerinden biri olarak bilinmektedir (Şeker ve ark., 2008). Çalışmanın yapıldığı Şırnak ve Mardin illerinde de yaşlı zeytin ağaçlarına rastlanılması bu bilgiyi doğrulamaktadır. Bu da bu illerimizde zeytin yetiştiriciliğinin yapılabilir olduğunun bir kanıtıdır fakat buna rağmen bölgedeki zeytin tarımı ne yazık ki hak ettiği şekilde gelişmemiştir. Bunun temel nedeni, bölgedeki özelliklede çalışmanın yapıldığı Şırnak ve Mardin illerimizdeki tarımsal teknik ve teknolojideki gelişmelerin zeytin tarımına yansıtılmamasıdır. Bu illerimizde toprak analizi yapmak suretiyle yeni tesis edilecek zeytinliklerde mutlaka modern zeytin yetiştiriciliğinin esasları göz önünde bulundurulmalı, adaptasyon çalışmaları arttırılmalı, başta sulama ve beslenme olmak üzere bakım işlemlerine de gereken önemin verilmesi gerekmektedir. Ayrıca bu illerimizde bölgede yetiştiriciliği yapılan Kilis yağlık, Nizip yağlık ve Halhalı gibi bölgenin önemli çeşitlerinin de bu illerimizde yetiştiriciliğinin denemesi gerekmektedir.

Çalışmamızda Mardin ve Şırnak illerindeki bazı zeytin genotiplerinin meyve ve yağ özellikleri belirlenmiştir, ancak bölgedeki zeytinciliğin gelişmesi için bu tür çalışmalar arttırılmalı ayrıca çalışmada yapılmayan yağ asitleri bileşenleri, tokoferol analizleri ve sterol analizlerininde yapılması gerekmektedir. Bölge zeytinin gen merkezlerinden biri olması nedeniyle Bölgedeki yerel genotiplerin standart zeytin çeşitleriyle akrabalık ilişkilerinin ortaya çıkması için moleküler düzeyde DNA analizlerinin de yapılması ve ıslah çalışmalarında kullanılması gerekmektedir. Bölgeye kurulacak bir zeytin ve zeytinyağı işletme tesisi ile bölge halkının zeytin yetiştiriciliğine teşvik edilmesi gerekmektedir. 
Çizelge 1. Zeytin genotiplerinin meyve ve çekirdeklerinin pomolojik değerleri.

\begin{tabular}{|c|c|c|c|c|c|c|c|c|c|c|c|c|}
\hline Genotip & $\begin{array}{c}\text { Çekirdek } \\
\text { Boyu } \\
\text { (mm) }\end{array}$ & $\begin{array}{l}\text { Çekirdek } \\
\text { Eni (mm) }\end{array}$ & $\begin{array}{c}100 \\
\text { Çekirdek } \\
\text { Ağırlığı (g) }\end{array}$ & $\begin{array}{l}\text { Çekirdek } \\
\text { Ağırlığı (g) }\end{array}$ & $\begin{array}{c}\text { Olgunluk } \\
\text { Indeksi }\end{array}$ & $\begin{array}{l}\text { Meyve Et } \\
\text { Oranı (\%) }\end{array}$ & Meyve Şekli & $\begin{array}{l}\text { Meyve } \\
\text { İndeksi }\end{array}$ & $\begin{array}{c}\text { Meyve } \\
\text { Boyu } \\
(\mathrm{mm})\end{array}$ & $\begin{array}{l}\text { Meyve Eni } \\
\quad(\mathrm{mm})\end{array}$ & $\begin{array}{l}100 \text { Meyve } \\
\text { Ağırlığı (g) }\end{array}$ & $\begin{array}{c}\text { Meyve } \\
\text { Ağırlığı (g) }\end{array}$ \\
\hline Kızılsu & $19.8 \pm 0.4$ & $9.4 \pm 2.1$ & $64.75 \pm 5.1$ & $0.64 \pm 0.2$ & $4.01 \pm 1.1$ & $81.74 \pm 3.5$ & Uzun oval & $1.53 \pm 0.6$ & $24.16 \pm 0.9$ & $15.72 \pm 0.4$ & $354.71 \pm 4.5$ & $3.55 \pm 2.4$ \\
\hline Kumçatı & $13.1 \pm 0.3$ & $7.48 \pm 0.9$ & $38.78 \pm 4.3$ & $0.38 \pm 0.1$ & $2.92 \pm 1.0$ & $88.06 \pm 5.4$ & Yuvarlağa yakın oval & $1.31 \pm 1.1$ & $21.49 \pm 0.7$ & $16.31 \pm 0.9$ & $324.93 \pm 6.2$ & $3.25 \pm 0.8$ \\
\hline Cizre & $14.28 \pm 0.2$ & $7.72 \pm 0.9$ & $46.44 \pm 4.2$ & $0.46 \pm \pm 0.6$ & $2.04 \pm 0.5$ & $85.76 \pm 0.9$ & Oval & $1.36 \pm 1.0$ & $21.74 \pm 0.7$ & $15.92 \pm 1.5$ & $326.21 \pm 4.4$ & $3.26 \pm 1.0$ \\
\hline Derik & $11.55 \pm 0.1$ & $5.01 \pm 0.4$ & $42.43 \pm 3.01$ & $0.42 \pm 0.3$ & $2.1 \pm 1.6$ & $87.46 \pm 5.3$ & Oval & $1.35 \pm 0.4$ & $22.10 \pm 1.1$ & $16.36 \pm 0.8$ & $338.45 \pm 5.1$ & $3.38 \pm 2.03$ \\
\hline Kızıltepe & $17.56 \pm 0.3$ & $7.88 \pm 3.02$ & $59.45 \pm 5.1$ & $0.59 \pm 0.1$ & $3.27 \pm 3.0$ & $84.02 \pm 2.4$ & Yuvarlağa yakın oval & $1.27 \pm 1.1$ & $22.56 \pm 0.3$ & $17.63 \pm 1.1$ & $372.19 \pm 3.1$ & $3.72 \pm 3.2$ \\
\hline Ayvalık & $15.59 \pm 0.2$ & $8.18 \pm 2.3$ & $72.85 \pm 5.0$ & $0.72 \pm 0.1$ & $3.9 \pm 0.2$ & $85.38 \pm 3.0$ & Yuvarlağa yakın oval & $1.22 \pm 1.0$ & $23.09 \pm 0.5$ & $18.85 \pm 0.8$ & $498.44 \pm 6.01$ & $4.98 \pm 0.9$ \\
\hline Gemlik & $14.84 \pm 0.2$ & $8.58 \pm 2.4$ & $69.05 \pm 2.1$ & $0.69 \pm 0.3$ & $5.56 \pm 0.6$ & $85.36 \pm 2.1$ & Yuvarlağa yakın oval & $1.25 \pm 2.0$ & $22.57 \pm 0.2$ & $18 \pm 1.3$ & $537.35 \pm 4.8$ & $5.37 \pm 0.3$ \\
\hline
\end{tabular}

Çizelge 2. Zeytin genotiplerinden elde edilen zeytin yağlarının kimyasal özellikleri

\begin{tabular}{lcc}
\hline Genotip & Peroksit $(\mathbf{m e q}$ g/ kg) & Toplam Fenol miktarı $(\mathbf{m g} / \mathbf{k g})$ \\
\hline Cizre & $18.53 \pm 0.35$ & $247.66 \pm 11.24$ \\
Kızıltepe & $16.53 \pm 0.15$ & $153.00 \pm 12.12$ \\
Kumçatı & $12.70 \pm 0.10$ & $232.66 \pm 27.32$ \\
Derik & $12.36 \pm 0.15$ & $292.33 \pm 8.08$ \\
Gemlik & $11.43 \pm 0.21$ & $359.66 \pm 33.65$ \\
Kızılsu & $11.13 \pm 0.31$ & $228.00 \pm 3.00$ \\
Ayvalık & $10.93 \pm 0.84$ & $374.33 \pm 9.07$ \\
\hline
\end{tabular}




\section{Kaynaklar}

Anonim, 1973. T.S.E. Yemeklik Zeytinyağı Muayene Metotları. TS-342, Dördüncü Baskı, Ankara.

AOAC, 1990. Official Methods of Analysis, 15th ed. Association of Analytical Chemists, Washington, DC., USA.

Canözer, Ö. 1991. Standart Zeytin Çeşitleri Kataloğu. Tarım ve Köyişleri Bakanlığı, Mesleki Yayınlar, No: 334-16, Ankara. 107 s.

Çavuşoğlu, A., Çakır, M. 1988. Modern Zeytincilik. Tarım ve Köyişleri Bakanlığı Mesleki Yayınlar, No.1, Ankara. 303 s.

Garcia, A., Brenes, M., Gaicia, P., Romero, C., Garrido, A. 2003. Phenolic Content of Commercial Olive Oils. Eur. Food Res. Technol. 216:520-525.

Kaniewski D., Van Campo E., Boiy T. 2012 Primary domestication and early uses of the emblematic olive tree: Palaeobotanical, historical and molecular evidence from the Middle East. Biological Reviews 87: 885-899 the American Oil Chemists'Society, 91:385394.

Kaynaş N., Sütçü A. R., Fidan A. E. 1996. Zeytinde Adaptasyon (Marmara Bölgesi). Atatürk Bahçe Kültürleri Merkez Araştırma Enstitüsü, Bilimsel Araştırma ve İncelemeler. Yayın No: 82, Yalova, $27 \mathrm{~s}$.

Kiritsakis, A., Markakis, P. 1987. Olive Oil: AReview. Department of Food Science and Human Nutrition. Michigon State Üniversity. East Lannding. Michigon 48824.

Mercuri AM, Mazzanti MB, Florenzano A. 2013. Olea, Juglans and Castanea: The OJC group as pollen evidence of the development of human-induced environments in the Italian peninsula. Quaternary International 303: 24-42.1576.

Nas, S., Gökalp, H.Y., Ünsal, M. 1992. Bitkisel Yağ Teknolojisi. Atatürk Üniversitesi Yayınları, No:723, Erzurum.

Owen, R.W., Mier, W., Giacosa, A.,Hul, W.E., Spiegelhalder, B., Barsch, H. 2000. Phonolic Compounds and Squlane in Olive Oils: The Concentration and Antioxidant Potential of Total Phenols, Simple Phenols, Secoiridoids, Lignans and Squalene, Food and Chemical Toxicology. 38:647-659.

Şeker, M., Gül, M.K., İpek, M., Kaleci, N., Yüzel, Z., Yılmaz, E., Topal, U. 2008. Zeytin (Olea europaea L.) Çeşitlerinin AFLP VE SSR Markörleri Polimorfizminin Yağ Asitleri ve Tokoferol Düzeyleri ile iliş̧kilendirilmesi. Proje No: TOVAG-3358. Temmuz 2008, Çanakkale.

Valamoti, S.M., Gkatzogia, E., Ntinou, M. 2018. Did Greek colonisation bring olive growing to the north? An integrated archaeobotanical investigation of the spread of Olea europaea in Greece from the 7th to the 1st millennium bc. Vegetation History and Archaeobotany 27:177-195.

Zheng W., Wang S.Y. 2001. Antioxidant Activity and Phonolic Compounds in Selected Herbs. J. Of Agr. And Food Chem., 49: 5165-5170.

Zohary D., Hopf M., Weiss E. 2012. Domestication of Plants in the Old World: The Origin and Spread of Domesticated Plants in Southwest Asia, Europe, and the Mediterranean Basin. 4th Edition, Oxford University Press. 